\title{
Manipulating the word frequency effect in free recall
}

\author{
GREGORY L. DUNLAP and LINDA L. DUNLAP \\ University of Iowa, Iowa City, Iowa 52242
}

\begin{abstract}
A recall advantage for common words was not evidenced when subjects generated or rated the list words on the basis of commonness and on a semantic, phonological, or orthographic basis prior to recall. Recall of the same set of words following only structural judgments of the words resulted in the usual recall advantage for common words. Results were not consistent with interpretations based only on the associative strengths of the recalled items. A process based on categorization of the words to be recalled was suggested as an alternative explanation.
\end{abstract}

In free recall experiments, common (high-frequency) words generally have a higher probability of recall than do uncommon (low-frequency) words, where commonness is defined by frequency of occurrence in natural language (e.g., Kucera \& Francis, 1967; Thorndike \& Lorge, 1944). Hall (1954) reported this frequency effect but suggested no theoretical explanation of the phenomenon. Subsequently, the recall advantage for common words has been attributed to the greater interrelatedness of common words relative to uncommon words. Deese $(1961,1965)$ interpreted the recall frequency effect in terms of the relative associative strengths of common and uncommon words. Common words, in general, have higher associative strengths than do uncommon words (as defined by the number of word associates that can be produced for a particular cue word). Deese proposed that recall of common words was facilitated by the interrelationships of the associates of the to-be-remembered words. Recall of any list item could potentially result in the recall of one or more other list items due to shared associates and a process of transfer of activation in memory. Recall of one item may lead to the retrieval of associates to that item. Retrieval of the associate may, in turn, lead to the recall of a second list item if the first and second list items share the associate. Recall of uncommon words should result in little facilitation by associative relations. Uncommon words are low in associative strength, and thus it is far less probable that two to-be-remembered uncommon words will be related in memory by a common associate. Sumby (1963) suggested, similarly, that uncommon words could be associatively related for recall. Further, he asserted that common words could be semantically associated but uncommon words could not be semantically associated due to the relative

Authorship is equal. We are indebted to Charles P. Thompson, James V. Hinrichs, and Richard R. Hurtig for helpful comments on an earlier version of this manuscript. Requests for reprints should be sent to Gregory L. Dunlap, Department of Psychology, University of lowa, lowa City, Iowa 52242. lack of associative strength for uncommon words. Thus, uncommon words may be organized on some less efficient basis for recall. On the basis of an analysis of recall functions for common and uncommon word lists, Sumby (1963, p. 450) concluded that "there is a tendency for high-frequency words to be associated semantically and low-frequency words to be associated phonetically." The notion of semantic relatedness of words in recall has more recently been incorporated into the memory model of Kintsch (1970). This model will not be reviewed here, but it is interesting to note that the recall frequency effect was considered in construction of the model. The effect was again attributed to the greater semantic relatedness of common words.

The present studies were designed to test the recall of common and uncommon words following encoding of those words on several specified bases. In particular, the subjects were directed to process the words as common or uncommon and on the basis of semantic, phonological, or orthographic properties.

\section{EXPERIMENT 1}

Experiment 1 was designed to test the recall of words that had been encoded on specific dimensions. In order to assure that the words to be recalled were encoded on the anticipated dimensions, a generation task was employed. Each subject generated words according to a series of statements presented by the experimenter. Each statement indicated that the word to be produced was either common or uncommon and was a member of a particular semantic category, rhymed with a particular word, or contained a particular letter. The subjectgenerated words comprised the set of to-be-remembered words.

Subjects were not informed prior to the generation task that the generated words would be used in a later recall task. An incidental leaming paradigm was employed in order to minimize recall or encoding 
strategies that would conflict with the processing strategy imposed by the generation statements.

Subjects generated words in either an experimenterpaced or a self-paced condition. The self-paced group was included to test for any effect of differential rehearsal time for the generated words in the paced condition. Pilot research indicated that common words were often generated faster than were uncommon words. Rehearsal of either the word generated or the generation process may occur in the time span between the presentation of generation statements in the paced condition.

It was predicted, on the basis of prior interpretations of the recall frequency effect, that common words encoded or processed on a semantic basis would have a high probability of recall relative to common words encoded on a phonological or orthographic basis. That is, semantic processing should emphasize the semantic interrelatedness of common words and lead to better recall. Semantic processing should not result in an increase in recall of uncommon words relative to phonological or orthographic processing. Low-frequency or uncommon words should have low associative strengths, and thus semantic processing should not be advantageous for later recall.

\section{Method}

Subjects. Forty undergraduate students enrolled in elementary psychology at the University of Iowa served as subjects. Each received partial course credit for participation. All subjects were native speakers of English. Subjects were randomly assigned to the experimental groups.

Materials. Each subject received a 72-page booklet. On each page was a statement that described a particular type of word. The words to be produced were either common or uncommon exemplars, and they represented a particular semantic category (category condition), rhymed with a particular word (rhyme condition), or contained a particular letter (structure condition). Category names were selected from the categories established by Battig and Montague (1969). An example statement is "A common type of flower." Each booklet contained two examples of 12 categories, 12 rhymes, and 12 structures, with one half of each type specified as common and the other half as uncommon. Thus, no booklet contained both a common and an uncommon exemplar of any unique category, thyme, or structure example. Two types of booklets were designed such that those instances that were specified as common in one set of booklets were specified as uncommon in the other set. Order of generation statements within each type of booklet was random with the restriction that one of each of the two examples of each word type appear in each half of the booklet.

Procedure. Subjects generated words according to the statement given on each page of the booklet. That is, subjects were instructed to generate and write down a word that was consistent with the statement on each page. Subjects were instructed not to respond with the same word to more than one statement. Subjects were assigned to either a paced or an unpaced condition. In the paced group, subjects generated one word every $15 \mathrm{sec}$. In the unpaced group, no limitation on generation time was imposed.

At the end of the generation task, subjects worked on a series of addition problems for $3 \mathrm{~min}$ as a distractor task. Following the distractor task, subjects were requested to recall as many words as they could remember having generated in the generation task. A period of $3 \mathrm{~min}$ was allowed for written recall. Subjects were not informed that they would be required to recall the generated words until the beginning of the recall task.
Instructions stated that the generation task and arithmetic task were designed to test the way in which people normally solve particular types of problems.

\section{Results and Discussion}

The number of generated words that were recalled in each experimental condition was the measure of primary interest in Experiment 1 . Some subjects, though, were not able to generate a word for each statement in the booklet. Potentially, then, not all conditions or subjects would have available the same number of items to be recalled, since the generated words served as the items to be recalled. The numbers of words produced by the subjects were entered into an analysis of variance that included the factors of pace, commonness of the word to be produced, and type of word to be produced. Significant main effects of pace $[F(1,38)=20.25$, $\mathrm{p}<.001]$, commonness $[\mathrm{F}(1,38)=18.97, \mathrm{p}<.001]$, and an interaction of pace and commonness $[F(1,38)=$ $13.02, p<.001]$ were obtained. The mean numbers of words generated for these conditions were presented in Table 1. These significant results all depend on the difficulty of producing uncommon words encountered by the paced subjects.

Due to the differences in number of words produced in the experimental conditions, the analysis of variance of recall was based on percentages of produced words recalled. The percentages of words recalled in the experimental conditions are presented in Table 1. This analysis resulted in a significant effect of type of word $[F(2,76)=29.49, p<.001]$. The paced group did not differ significantly from the unpaced group in recall. Additionally, no interactions involving pace reached significance. Since the unpaced group was included only for methodological considerations, the factor of pace was eliminated in a second analysis of variance based on the percentage of produced words recalled. This analysis of variance again resulted in a main effect of type of word $[F(2,78)=28.83, p<.001]$. Paired comparisons using Dunn's test indicated that category

Table 1

Number of Words Produced and Recall Percentages from Experiment 1

\begin{tabular}{|c|c|c|c|c|}
\hline \multirow[b]{2}{*}{ Group } & \multicolumn{2}{|c|}{ Common } & \multicolumn{2}{|c|}{ Uncommon } \\
\hline & Mean & SD & Mean & $\mathrm{SD}$ \\
\hline & \multicolumn{4}{|c|}{ Words Produced } \\
\hline $\begin{array}{l}\text { Paced } \\
\text { Unpaced }\end{array}$ & $\begin{array}{l}35.8 \\
36.0\end{array}$ & $\begin{array}{l}.75 \\
.00\end{array}$ & $\begin{array}{l}34.2 \\
35.8\end{array}$ & $\begin{array}{r}2.34 \\
.66\end{array}$ \\
\hline & \multicolumn{4}{|c|}{ Percentages of Produced Words Recalled } \\
\hline $\begin{array}{l}\text { Paced } \\
\text { Category } \\
\text { Rhyme } \\
\text { Structure }\end{array}$ & $\begin{array}{l}46.3 \\
30.3 \\
28.8\end{array}$ & $\begin{array}{l}24.0 \\
10.6 \\
16.9\end{array}$ & $\begin{array}{l}50.8 \\
18.0 \\
27.3\end{array}$ & $\begin{array}{l}20.2 \\
14.8 \\
18.0\end{array}$ \\
\hline \multicolumn{5}{|l|}{ Unpaced } \\
\hline $\begin{array}{l}\text { Category } \\
\text { Rhyme } \\
\text { Structure }\end{array}$ & $\begin{array}{l}37.9 \\
23.3 \\
27.1\end{array}$ & $\begin{array}{l}18.0 \\
13.6 \\
14.9\end{array}$ & $\begin{array}{l}37.8 \\
24.2 \\
22.7\end{array}$ & $\begin{array}{l}17.5 \\
14.6 \\
12.3\end{array}$ \\
\hline
\end{tabular}


words were recalled better than were rhyme or structure words $[t(1,76)=6.76, p<.01$, and $t(1,76)=6.06$, $p<.01]$, with no difference in the recall of rhyme and structure words $[t(1,76)<1]$. Mean percentages of generated words recalled were $43.2,24.0$, and 26.5 for the category, rhyme, and structure conditions, respectively. In all subsequent analyses of Experiment 1, the paced and unpaced groups were combined and treated as a single group.

Although no main effect of commonness or interaction of commonness with type of word was obtained, an absolute difference between the percentage recalled in the common and uncommon conditions was present when semantic encoding was not required (i.e., in the rhyme and structure conditions). In order to test the hypothesis that the semantic condition alone led to the lack of an effect of commonness in the overall analysis, a separate analysis of variance was conducted in which the data for the semantic condition were excluded. Again, though, no main effect of commonness or interaction of commonness with type of word was obtained $[\mathrm{F}(1,39)=3.24$ and $\mathrm{F}(1,39)=1.16$, respectively $]$.

Of particular interest in the recall results is the lack of difference in recall for common and uncommon words, contrary to considerable prior research (e.g., Deese, 1961; Hall, 1954; Sumby, 1963). This lack of difference may be due to the requirement that all produced words be processed as members of specified categories. That is, each word was generated by a subject on the basis of being in one of six specific categories defined by commonness and type of word. Categorization of the recall items on these dimensions may eliminate the recall advantage usually evidenced for highfrequency words. In order to test the hypothesis that subjects categorized the recall words, subjects' recall protocols were evaluated for evidence of clustering of category items in recall. Clustering has generally been observed in the recall of categorized lists of words (e.g., Bousfield, 1953; Cofer, Bruce, \& Reicher, 1966; Cohen, 1963). Roenker, Thompson, and Brown (1971) proposed a method of calculating the degree of clustering in recall based on the number of times that two sequentially recalled items are members of the same category. Roenker et al. suggested calculating a score labeled the "adjusted ratio of clustering score," which is a ratio of the number of observed category repetitions above the number of such repetitions expected by chance to the total number of possible repetitions above the number expected by chance. Thus, an adjusted ratio of clustering score of .00 represents clustering at a level expected by chance, and a score of 1.00 represents optimal or perfect clustering in recall. In the present experiment, the mean adjusted ratio of clustering score for all subjects was .372 , which was significantly greater than would be expected by chance $[t(1,39)=5.59$, $p<.001]$. Thus, it appears that subjects did recall the items on the basis of the categories provided by the generation statements. This interpretation for the lack of difference in the recall of common and uncommon words will be considered in more detail after consideration of several alternatives.

Three alternative explanations to account for this lack of difference are (1) that the generated or recalled words were not different in frequency, (2) that the words were unusual in some sense not particular to the subjects producing the words and would be similarly recalled by other subjects as well, and (3) that the words generated, if different in frequency, were particular to the subjects producing the words and, thus, easy to recall by the subjects.

With respect to the first possible explanation, frequency of the words generated by the subjects was evaluated. An analysis of frequency was based on the median frequencies for the common and uncommon conditions, with the levels of type and subjects serving as the replication factors. Frequency ratings were based on Kucera and Francis (1967). The means of the median frequencies obtained for the experimental conditions are presented in Table 2 . The effect of commonness was significant $[t(1,119)=10.00$, $\mathrm{p}<.001]$, with means of the median frequencies for the common and uncommon words of 38.66 and 4.04 per 1.014 million, respectively. The result of a similar analysis based on mean frequencies was equivalent, with mean frequencies of 199.37 and 32.44 per 1.014 million for the common and uncommon words, respectively $[t(1,119)=7.70, p<.001]$. Clearly, then, subjects followed instructions and produced high. frequency words in the common conditions and lowfrequency words in the uncommon conditions.

Since, in each experimental condition, words of differing frequencies were generated, it is possible that subjects recalled only common words, even though the means of the medians for the conditions varied. The median frequencies of the recalled words for the experimental conditions are presented in Table 2. No statistical analysis of these data was attempted since not all subjects recalled a word in every experimental condition. The medians do indicate, though, that subjects recalled both common and uncommon words and that the result of no difference in recall for common and uncommon words is not due to recall of words of equal frequency in these two conditions.

It appears, then, that subjects did indeed generate

Table 2

Mean Median Frequencies of Produced and Recalled Words (Combined Groups) from Experiment 1

\begin{tabular}{lccccc}
\hline & \multicolumn{2}{c}{ Produced Words } & & \multicolumn{2}{c}{ Recalled Words } \\
\cline { 2 - 3 } \cline { 5 - 6 } & $\mathrm{C}$ & $\mathrm{U}$ & & $\mathrm{C}$ & $\mathrm{U}$ \\
\hline Category & 29.11 & .91 & & 23.0 & .0 \\
Rhyme & 44.45 & 6.20 & & 55.0 & 2.0 \\
Structure & 77.78 & 2.95 & & 71.0 & .0 \\
\hline
\end{tabular}

Note-All frequencies refer to number of occurrences per 1.014 million words. $C=$ common, $U=$ uncommon. 
and recall common and uncommon words. The two remaining alternative explanations were evaluated in Experiments 2 and 3 . Since the unpaced group performed comparably to the paced group in terms of recall, the unpaced group was not included in Experiments 2 and 3.

\section{EXPERIMENT 2}

Experiment 2 was designed to test the hypothesis that the equal recall of common and uncommon words in Experiment 1 was due to some unique characteristic of the words generated. Experiment 2 attempted to demonstrate the recall frequency effect employing the generated words from Experiment 1 as stimuli. Subjects in Experiment 2 processed the words generated in Experiment 1 on a structural basis. Thus, subjects were presented the words but were not directed to process the words on a dimension such as commonness.

\section{Method}

Subjects. Twenty undergraduates enrolled in elementary psychology at the University of Iowa served as subjects. Each received partial course credit for participation. All subjects were native speakers of English.

Materials. Each subject received a 72-page booklet with one word on each page. Each word of a booklet had been generated by a matched subject from the paced condition in Experiment 1 . When no word had been generated by the paced subject in Experiment 1, due to the time constraints, a word that was generated by an unpaced subject for an equivalent statement was selected.

Procedure. The subjects' task was to determine and record the number of vowels, consonants, and syllables in each word. For each word, a period of $15 \mathrm{sec}$ was allowed to make the three structural judgments. The judgment task was followed by the distractor and recall tasks, as in Experiment 1. The words in the booklet served as the target items for recall

\section{Results and Discussion}

An analysis of the number of words recalled resulted in a significant effect of commonness of the generated word $[F(1,19)=4.81, p<.05]$. Common words were recalled better than were uncommon words, with respective means of 4.8 and 2.9 words recalled. The mean number of words recalled and the median frequencies of the recalled words are presented in Table 3 . No main effect of type of word or interaction of type of word with commonness was obtained $[\mathrm{F}(2,38)=2.56$ and $F(2,38)=1.09$, respectively .

Evaluation of the recall protocols in Experiment 2 showed no evidence of clustering of responses in recall on the basis of the categories established in Experiment 1 . The mean adjusted ratio of clustering score of -.129 indicated that the level of clustering was not significantly different from that expected by chance $[\mathrm{t}(1,19)=1.09]$.

The results of Experiment 2 demonstrate the usual recall frequency phenomenon in that common words were recalled with a greater probability than were uncommon words. The results of Experiment 1, then, do not appear to be specific to the particular words generated but to the requirement that the words be processed on specific dimensions.

As discussed above, it is also possible that the words generated in Experiment 1 were particular to the subjects who produced them. The equivalent recall of common and uncommon words in Experiment 1, then, could be specific to the particular words generated and to the particular subjects who generated the words. Experiment 3 was designed to test this hypothesis.

\section{EXPERIMENT 3}

Experiment 3 was designed to test the recall of the words generated in Experiment 1 when the generated words are presented to a new sample of subjects and the words are encoded on the same dimensions as in Experiment 1. That is, the subjects in Experiment 3 processed the generated words from Experiment 1 on the basis of whether each word was common or uncommon and whether each word represented a particular category, thymed with a particular word, or contained a particular letter. The words processed on these bases were then tested for recall.

\section{Method}

Subjects. Twenty undergraduate students enrolled in elementary psychology at the University of lowa served as subjects. Each subject received partial course credit for participation. All subjects were native speakers of English.

Materials. Each subject received a 72-page booklet that was similar to those used in Experiment 1. The statement on each page was followed by a word that had been generated

Table 3

Summary Statistics for Experiment 2

\begin{tabular}{|c|c|c|c|c|c|c|}
\hline & \multicolumn{4}{|c|}{ Number of Words Recalled } & \multirow{2}{*}{\multicolumn{2}{|c|}{$\begin{array}{l}\text { Median Frequencies } \\
\text { of Recalled Words }\end{array}$}} \\
\hline & \multicolumn{2}{|c|}{ Common } & \multicolumn{2}{|c|}{ Uncommon } & & \\
\hline & Mean & $\mathrm{SD}$ & Mean & SD & Common & Uncommon \\
\hline Category & 1.80 & .8 & 1.40 & 1.5 & 23.0 & 1.0 \\
\hline Rhyme & 1.65 & 1.4 & .65 & 1.0 & 56.0 & 2.0 \\
\hline Structure & 1.30 & 1.2 & .85 & .9 & 75.0 & 1.5 \\
\hline
\end{tabular}

Note-All frequencies refer to number of occurrences per 1.014 million words. 
by a matched subject from the paced condition in Experiment 1 . When no word had been generated by the paced subject in Experiment 1, due to the time constraints, a word that was generated by an unpaced subject for an equivalent statement was selected. The words, then, were the same words used in Experiment 2.

Procedure. Subjects rated the word on each page of the booklet on the basis of how well it was described by the statement on that page. Ratings were on a scale from 1 to 7 , with 1 being "poor" and 7 being "good." Subjects rated one word every $15 \mathrm{sec}$. The rating task was followed by the distractor and recall tasks, as in Experiment 1 . Recall was of the rated words.

\section{Results and Discussion}

An analysis of variance based on the number of words recalled resulted in a significant effect of the type of word $[F(2,38)=54.58, p<.001]$. This effect is equivalent to the type effect obtained in Experiment 1, with category words being recalled better than rhyme or structure words $[t(1,38)=9.05, p<.01$, for both comparisons, using Dunn's test]. There was no numerical or statistical difference between recall of the rhyme and structure words. Mean numbers of words recalled in the category, rhyme, and structure conditions were 9.0, 3.2, and 3.2 words, respectively. Again, no recall difference for common and uncommon words was obtained. The mean number of words recalled and the median frequencies of the recalled words are presented in Table 4.

The recall protocols for the subjects in Experiment 3 provided evidence that the subjects encoded and recalled the words on the basis of the categories provided by the statements in the booklets. A significant mean adjusted ratio of clustering score of .289 was obtained $[\mathrm{t}(1,19)=3.40, \mathrm{p}<.01]$.

The results of Experiment 3 indicate that the equal level of recall for common and uncommon words in this experiment and in Experiment 1 is not due to the generation and recall of words particular to the subjects in Experiment 1.

Although not critical to the interpretation of the present experiments, it is interesting to note that the generation effect reported by Slamecka and Graf (1978) is evidenced in the results of these experiments. That is, subjects recalled self-generated words better than they did words generated by another subject (which is, essentially, an experimenter-generated condition). In Experiment 1, the mean percentage of words recalled was 31.2 ; in Experiment 3, the mean percentage of words recalled was 21.4. Experiments 1 and 3, then, serve as an independent replication of the generation effect reported by Slamecka and Graf.

\section{GENERAL DISCUSSION}

Experiments 1 and 3 demonstrated that semantically encoded or processed words are recalled with a higher probability than are words processed on a phonological or orthographic basis. This result is consistent with the emphasis of Sumby (1963) on semantic processing in recall. The effect of semantic processing on memory is also central to the more recent levels-of-processing theory (Craik \& Lockhart, 1972; Craik \& Tulving, 1975). The present data again demonstrate the importance of semantic processing, but they are not presented with the intent to provide support for any particular theoretical explanation of the phenomenon.

The empirical phenomenon of greater recall probability for common words relative to uncommon words was demonstrated in Experiment 2. Experiments 1 and 3 demonstrated that the recall advantage for common words could be eliminated if the words to be recalled were classified as common or uncommon and as a member of a particular category, as rhyming with a particular word, or as containing a particular letter. Although the structural tasks of Experiments 2 and 3 differ to some degree, the results of Experiment 2 at least tentatively indicate that encoding the words on a structural basis alone cannot account for the equal recall of common and uncommon words in the structure condition in Experiment 3.

A model of recall based on associative strength only would not appear adequate to account for the present results. Contrary to the predictions of such a model, common words and uncommon words were recalled equally well in Experiments 1 and 3. As suggested by Sumby (1963), semantic encoding did result in a higher probability of recall than did other modes of encoding, but, contrary to Sumby, recall of both common and uncommon words was facilitated by semantic encoding.

Alternatively, the recall frequency effect and the

Table 4

Summary Statistics for Experiment 3

\begin{tabular}{|c|c|c|c|c|c|c|}
\hline & \multicolumn{4}{|c|}{ Number of Words Recalled } & \multirow{2}{*}{\multicolumn{2}{|c|}{$\begin{array}{l}\text { Median Frequencies } \\
\text { of Recalled Words }\end{array}$}} \\
\hline & \multicolumn{2}{|c|}{ Common } & \multicolumn{2}{|c|}{ Uncommon } & & \\
\hline & Mean & $\mathrm{SD}$ & Mean & SD & Common & Uncommon \\
\hline Category & 4.95 & 2.4 & 4.10 & 1.8 & 9.5 & .0 \\
\hline Rhyme & 1.55 & 1.1 & 1.70 & 1.1 & 65.0 & 1.0 \\
\hline Structure & 1.85 & 1.1 & 1.40 & 1.2 & 34.5 & 1.0 \\
\hline
\end{tabular}

Note-All frequencies refer to number of occurrences per 1.014 million words. 
present results can be explained in terms of a process of categorization of the list items. Categorization has repeatedly been demonstrated to exert a strong influence on the free recall of list items (e.g., Bousfield, 1953). Bower (1972) has suggested that acquisition and recall of a word list reflects three processes: (1) learning the categories represented by the words, (2) learning to relate the category names with the relevant list items, and (3) recall of the category names and the associated items. Relevant to the interpretation of these experiments is the empirical phenomenon that recall of lists constructed of high-frequency category exemplars is better than is recall of lists constructed of low-frequency category exemplars (Bousfield, Cohen, \& Whitmarsh, 1958; Cofer et al., 1966). Category exemplar frequency is determined by the frequency with which subjects produce a particular exemplar when given the category name (e.g., Battig \& Montague, 1969).

In Experiments 1 and 3, the gross category of "words" was subdivided into six categories of words on the basis of the provided generation statements. Subjects generated words that they judged to be good exemplars of the six categories. In these experiments, then, all list words are similar to high-frequency category exemplars. For example, a word generated for the category of "an uncommon type of flower" would presumably be a good exemplar of that category, even though that word's frequency of occurrence among all types of words would be very low. In this sense, both the common and uncommon words in Experiments 1 and 3 were equally good exemplars of their respective categories. Although no association ratings are available for the six categories used in these experiments, the similarity between the generation procedure used in Experiment 1 and the procedures used to obtain category frequency ratings (e.g., Battig \& Montague, 1969) is great. All words in Experiments 1 and 3 are conceivably "high-frequency" exemplars of their respective categories. The category frequency results of Bousfield et al. (1958) and Cofer et al. (1966) would predict no difference in recall of common and uncommon words in Experiments 1 and 3 , since all items are argued to be of equal category frequency. This prediction is supported by the obtained results.

The categorical recall interpretation is also consistent with the recall frequency effect obtained in Experiment 2 and in prior research (e.g., Deese, 1961). In such a task, the gross category of "words" is not subdivided into finer categories. Within the category of words, the uncommon words generated in Experiment 1 are lowfrequency category exemplars. Uncommon words, then, should be and are recalled with lower probability than are common words.

The results of the analyses of clustering by category in order of recall also support the hypothesis that subjects in Experiments 1 and 3 categorized the words to be recalled. Significant clustering on the basis of the six categories formed by the combinations of commonness and type of word was observed in Experiments 1 and 3. In Experiment 2, in which the usual recall advantage for high-frequency words was obtained, no significant clustering in recall was observed.

The series of experiments reported here indicate that the recall advantage generally evidenced for highfrequency words can be readily manipulated. This result is inconsistent with interpretations based only on associative strength of list items. It is suggested that probability of recall is dependent on categorization of the list items, with high-frequency category exemplars being more frequently recalled then low-frequency category exemplars. The category names of "common words" and "uncommon words" both facilitate recall.

\section{REFERENCES}

Battig, W. F., \& Montague, W. E. Category norms for verbal items in 56 categories: A replication and extension of the Connecticut category norms. Journal of Experimental Psychology Monograph, 1969, 80, 1-46.

Bousfield, W. A. The occurrence of clustering in the recall of randomly arranged associates. Journal of General Psychology, $1953,49,229-240$

Bousfield, W. A., Cohen, B. H., \& Whitmarsh, G. A. Associative clustering in the recall of words of different taxonomic frequencies of occurrence. Psychological Reports, 1958, 4, 39-44.

Bower, G. H. A selective review of organizational factors in memory. In E. Tulving \& W. Donaldson (Eds.), Organization of memory. New York: Academic Press, 1972.

Cofer, C. N., Bruce, D. R., \& Reicher, G. M. Clustering in free recall as a function of certain methodological variations. Journal of Experimental Psychology, 1966, 71, 858-866.

CoHEN, B. H. Recall of categorized word lists. Journal of Experimental Psychology, 1963, 66, 227-234.

Craik, F. I. M., \& Lockhart, R. S. Levels of processing: A framework for memory research. Journal of Verbal Learning and Verbal Behavior, 1972, 11, 671-684.

Craik, F. I. M., \& Tulving, E. Depth of processing and the retention of words in episodic memory. Journal of Experimental Psychology: General, 1975, 104, 268-294.

DEEsE, J. From the isolated verbal unit to connected discourse. In C. N. Cofer (Ed.), Verbal learning and verbal behavior. New York: McGraw-Hill, 1961.

DEESE, J. The structure of associations in language and thought. Baltimore, Md: Johns Hopkins Press, 1965.

HaLL, J. F. Learning as a function of word frequency. American Journal of Psychology, 1954, 67, 138-140.

KInTSCH, W. Models for free recall and recognition. In D. A. Norman (Ed.), Models of human memory. New York: Academic Press, 1970.

KuCEra, H., \& Franc1s, W. N. Computational analysis of presentday American English. Providence, R.I: Brown University Press, 1967.

Roenker, D. L., Thompson, C. P., \& Brown, S. C. Comparison of measures for the estimation of clustering in free recall. Psychological Bulletin, 1971, 76, 45-48.

Slamecka, N. J., \& Graf, P. The generation effect: Delineation of a phenomenon. Journal of Experimental Psychology: Human Learning and Memory, 1978, 4, 592-604.

Sumby, W. H. Word frequency and serial position effects. Journal of Verbal Learning and Verbal Behavior, 1963, 1, 443-450.

Thonndike, E. L., \& Longe, I. The teacher's word book of 30,000 words. New York: Columbia University Press, 1944.

(Received for publication May 21, 1979; revision accepted August 25, 1979.) 